\title{
Identifying Effective Features and Classifiers for Short Term Rainfall Forecast Using Rough Sets Maximum Frequency Weighted Feature Reduction Technique
}

\author{
Sudha Mohankumar ${ }^{1}$ and Valarmathi Balasubramanian ${ }^{2}$ \\ ${ }^{1}$ Information Technology Department, School of Information Technology and Engineering, VIT University, Vellore, India \\ ${ }^{2}$ Software and Systems Engineering Department, School of Information Technology and Engineering, VIT University, \\ Vellore, India
}

Precise rainfall forecasting is a common challenge across the globe in meteorological predictions. As rainfall forecasting involves rather complex dynamic parameters, an increasing demand for novel approaches to improve the forecasting accuracy has heightened. Recently, Rough Set Theory (RST) has attracted a wide variety of scientific applications and is extensively adopted in decision support systems. Although there are several weather prediction techniques in the existing literature, identifying significant input for modelling effective rainfall prediction is not addressed in the present mechanisms. Therefore, this investigation has examined the feasibility of using rough set based feature selection and data mining methods, namely Naïve Bayes (NB), Bayesian Logistic Regression (BLR), Multi-Layer Perceptron (MLP), J48, Classification and Regression Tree (CART), Random Forest (RF), and Support Vector Machine (SVM), to forecast rainfall. Feature selection or reduction process is a process of identifying a significant feature subset, in which the generated subset must characterize the information system as a complete feature set. This paper introduces a novel rough set based Maximum Frequency Weighted (MFW) feature reduction technique for finding an effective feature subset for modelling an efficient rainfall forecast system. The experimental analysis and the results indicate substantial improvements of prediction models when trained using the selected feature subset. CART and J48 classifiers have achieved an improved accuracy of $83.42 \%$ and $89.72 \%$, respectively. From the experimental study, relative humidity2 (a4) and solar radiation (a6) have been identified as the effective parameters for modelling rainfall prediction.

ACM CCS (2012) Classification: Computing methodologies $\rightarrow$ Machine learning $\rightarrow$ Machine learning algorithms $\rightarrow$ Feature selection;
Information systems $\rightarrow$ Information retrieval $\rightarrow$ Retrieval tasks and goals $\rightarrow$ Clustering and classification; Applied computing $\rightarrow$ Operations research $\rightarrow$ Forecasting

Keywords: rainfall prediction, rough set, maximum frequency, optimal reduct, core features and accuracy

\section{Introduction}

Rainfall forecast serves as an important disaster prevention tool. Agricultural yields and agriculture based industrial development more often than not, rely on natural water resources like rain and rain-bound static water bodies for productivity. Rainfall prediction or forecasting is not a simple process, rather it is a demanding scientific task; precise prediction is a challenging job for meteorological scientists across the world. Prediction demands attention as the atmospheric factors that determine the rainfall event are highly dynamic. Thus, determining the future from the available historical data is not a simple task as it is influenced by current dynamics of the atmosphere. [1] reinstated the immense importance of prediction of the torrential downpour to minimize natural disasters before the events occur. As reported in [2], Weather Research Forecast (WRF) model as a suitable heavy rainfall event prediction model. The experimental results proved that their pro- 
posed model could predict rainfall in significant consistency with real measurements. [3] described a feature selection approach using genetic algorithm for heavy rainfall predictions in South Korea. They used weather data collected from European Medium Range Weather Forecast centre between 1989 and 2009. Despite the existence of several works related to rainfall prediction, there is always a demand for better techniques for prediction due to the magnitude of impact rainfall has on the environment.

The foremost intent of this research is to accomplish improved prediction accuracy through the use of effective weather parameters using proposed rough set feature selection and data mining methods. This research is different from previous work as it delves into identifying the influencing features that enable efficient rainfall forecast. The proposed model not only focuses on feature reduction but also on finding a list of parameters contributing to precision instead of just finding a subset or attaining dimensionality reduction.

\section{Foundation}

Rough Set Theory (RST), as proposed by Z. Pawlak in 1982, is a mathematical model that deals with vague and imperfect knowledge. RST does not require any prior knowledge or additional information about the data [4] [5] [6]. In rough set, data analysis starts from a table referred to as decision or information table representing an information system. Rough set having a wide scope has been adopted in a wide range of scientific and medical applications, especially in the field of pattern recognition, data mining, machine learning, process control and knowledge representation systems [7] [8] [9]. Rough sets have been used in various medical, meteorological applications for knowledge discovery [10].

\section{Definition 1. Information System}

Let an information system be $I=\{X, A, V, S\}$, where $X$ is a universal set that constitutes the domain objects of the system. $\{A\} \rightarrow\{C \cup D\}$ is a feature set that includes condition features and the decision feature. $V \rightarrow(V r X r \in R V r)$ is a set of features. $V r$ is the feature value range of $r \in A S: X \times A \rightarrow V$ is an information function, which designates each object feature value in $V$ that constitutes an information system.

\section{Definition 2. Decision Table}

It is a finite set of objects that constitute an information system description represented as a table. The decision table consists of a finite set of conditional and decision features. The sample information table of this rainfall forecast system is presented in Table 1 . The dataset has eight conditional attributes or features represented as (a1, a2, a3, a4, a5, a6, a7, and a8) and one decision variable (Rf).

\section{Definition 3. Approximation Space}

In an information system $I=\{X, A, V, S\}$, the rough set concept can be defined by means of topological operations, i.e., interior and closure, called approximations. The key concept of the presented rough set approach is the mathematical formulation of the concept of equality of sets defined as approximation space [6].

Definition 4. Discernible and Indiscernible Relation

For an information system $I=(O, A), O \rightarrow\{\}$ is a non-empty set of objects and $A \rightarrow\{\}$ a non-empty set of features where each $\{S A\} \rightarrow$ subset of features of $\{A\}$. ' $\mathrm{R}$ ' is the equivalence relation called indiscernibility relation on the set $\{I\}$ that contains the elements with similar feature values and complements of it as discernible relation. This equivalence relation partitions the universe to several classes and union of all equivalence relations form the set $\{I\}$. The equivalence class of $R$ determined by element $x$ is denoted by $R(x)$.

Definition 5. Lower and Upper Approximation Let $I=(U, A)$ and let $B \subseteq A$ and $X \subseteq U$,we can approximate $X$ using only the information obtained in B by constructing the $B$-lower and $B$-upper approximations of $X$ denoted as $\underline{B} X$ and $\bar{B} X$, respectively. A lower approximation set of $X$ is the set of all elements of $U$ that are certainly classified as elements of $X$, where $\underline{B} X=\left\{x /[X]_{B} \subseteq X\right\}$. Upper approximation set of $X$ contains all data which can possibly be classified as belonging to the set $X$ is $\bar{B} X=\left\{x /[x]_{B} \cap X \neq \varphi\right\}$. Approximation accu- 
racy is determined using the lower and upper approximation space.

\section{Definition 6. Reduct and Core}

The two fundamental concepts of RST are core and reduct. The reduct set $\{R\}$ is the indispensable part of an information system with all possible subsets of features. Reduct set can discern all objects as a complete feature set $\{A\}$. The core is the indispensable feature of reducts, where

$$
\text { Core }=\{R 1\} \cap\{R 2\} \cap\{R 3\} \ldots \cap\{R n\}
$$

The proposed rough set based Maximum Frequency Weighted (MFW) feature reduction model is designed based on RST. This model is used to reduce the feature space of meteorological (rainfall) dataset and to identify the significant features. Initially, the required possible combinations of feature reduct sets are generated using Rosetta (http://rosetta.org), which is an open source Rough Set Toolkit for data analysis (Rosetta) [11]. The required target input for the proposed algorithm is determined using Rosetta's genetic algorithm based feature reduction technique. These sets of reducts are then used in identifying the effective features based on the novel feature ranking based frequency weighted feature reduction approach. In the next phase, the impact of succeeding set of feature subsets is evaluated based on the performance of classification models. The proposed algorithm background and implementation details are described in subsection 5.2. The detailed working model and the performance outcomes are discussed in the experimental results and discussion sections.

\section{Related Works}

[12] proposed a feature selection approach using genetic algorithm to select key features from the complete feature set using data mining methods. They proposed an improved Naïve Bayes classifier technique and explored the use of genetic algorithms (GAs) for selecting a subset of the input features in the classification. [13] described Johnson selection algorithm and the Object Reduct using Feature Weighting technique (ORFW) for reduct computation. Both algorithms aim at reducing the number of features in the dataset based on discernibility matrix. [14] described a modified binary discernibility matrix for feature selection algorithm based on discernibility matrix that dealt directly with inconsistent decision-making system. Ordering and simple link technique in the algorithm reduced the size of the input table, which, in turn, reduced the computation and storage space. [15] reported a two-step feature selection technique. A discretisation process of reducing the domain of a continuous features with irreducible and an optimal set of cuts was adopted based on the discernibility matrix.

[16] described a reduct optimization method based on the conditional features to generate representative data to simplify the discernibility matrix. [17] described a reduct construction method based on discernibility matrix simplification. Elements of a minimum discernibility matrix are either the empty set or singleton subsets, in which the union derives a reduct using heuristic reduct algorithms. [18] investigated Support Vector Machine (SVM) classifier as a suitable model for rainfall forecasting. [19] utilized a new fuzzy based feature selection approach for a medical dataset in tumour diagnosis. In this approach, feature selection method based on the fuzzy gain ratio under the framework of fuzzy RST has been described by experiment results. They have demonstrated the effectiveness of the proposed approach by comparing the proposed approach with several other approaches on three real world tumour datasets in gene expression. This model will be useful for various medical data diagnosis. [20] proposed a new feature selection algorithm using analogical matrix. The proposed algorithm can reduce time complexity and spatial complexity after feature selection without breaking the coherence of the information contained in the decision table.

[21] have proposed and presented a new feature selection method based on rough set approach integrated with the Bee Colony Optimization (BCO). Their proposed approach generates minimal reducts for medical datasets. Further, they had analysed the existing methods, such as Quick Reduct, Entropy Based Reduct, and other hybrid Rough Set methods like GA, Ant Colony Optimization (ACO) and Particle Swarm Optimization. Based on the analysis 
and experimentation, they had concluded that BCO algorithm based rough set as optimum exibited consistent and better performance when compared with other methods. Therefore, they had recommended the Bee Colony Based Reduct (BeeRSAR) approach for the numerical datasets.

[22] described an approach for reduct computation based on ACO methodology. The proposed approach has three steps: (1) updated pheromone trails are directed to the nodes that are visited by the ants rather than the edges connecting these nodes, (2) the pheromone trail values are limited between max and min trails, (3) heuristic values are dynamically estimated during the Ant Colony based search. The outputs of experimentation have shown that the proposed approach can produce a short reduct with fewer iterations in comparison to other ACO based feature selection approaches. [23] described the application of rough set concept for hybrid data which involved different data with imperfect knowledge, which can be handled efficiently using rough set. [24] described the use of rough sets concept for multi-criteria data analysis. [25] reported a new classification approach by integrating feature selection algorithms to enhance predictor accuracy. [26] created a rainfall prediction model based on Bayesian classifier. In Bayesian approach, the model performed well for those datasets with predictor class label; however, in the absence of predictor class label for a given dataset, the Bayesian classification model assumed the record with zero probability thereby affecting the overall accuracy. On the other hand, [27] formulated a new reduct optimization method based on the condition attributes to simplify the discernibility matrix and the complexity of the attribute reduction. Analogical matrix based attributed reduction algorithm is a new approach towards attribute reduction. Experimental evaluation exposed that it can reduce the time complexity and spatial complexity without breaking the coherence of the information contained in the decision table [28].

In general, rainfall prediction is an important disaster prevention task; hence the demand for new methodologies in this field of study never subsides [29] [30]. Therefore, the main intent of this research is to identify the most influencing weather parameters using rough set approach. This proposed model is an attempt to identify the parameters that can improve the prediction efficiency of the classification models without blindly reducing the feature vector. This study introduces a novel MFW feature reduction technique for estimating the significance of the features based on ranking to enhance the prediction accuracy.

\section{Materials and Methods}

Dataset: The daily rainfall data, measured in millimetre $(\mathrm{mm})$, were obtained from the department of meteorology, Tamil Nadu Agricultural University (TNAU), Coimbatore, India. The assessment of rainfall prediction data for a period of 29 years from 1984 to 2013 consisted of observatory records of eight atmospheric parameters. The dataset had $0.5 \%$ of missing data and $0.3 \%$ of outliers in the raw dataset, which was identified and removed during data

Table 1. Daily rainfall observatory records (1984-2013).

\begin{tabular}{|c|c|c|c|c|c|c|c|c|}
\hline $\mathbf{a 1}$ & $\mathbf{a 2}$ & $\mathbf{a 3}$ & $\mathbf{a 4}$ & $\mathbf{a 5}$ & $\mathbf{a 6}$ & $\mathbf{a 7}$ & $\mathbf{a 8}$ & $\mathbf{R f}$ \\
\hline Celsius & Celsius & $\mathbf{\%}$ & $\mathbf{\%}$ & $\mathbf{K m} / \mathbf{H r s}$ & $\mathbf{K C a l o r i e s}$ & $\mathbf{H r s}$ & $\mathbf{m m}$ & $\mathbf{m m}$ \\
\hline \hline 28 & 14 & 94 & 55 & 7.4 & 260 & 10.2 & 3.4 & 0 \\
\hline 28 & 18 & 95 & 51 & 9 & 232 & 9.4 & 4.2 & 0 \\
\hline 28.5 & 18 & 95 & 42 & 7.4 & 200 & 8.1 & 4 & 0 \\
\hline 28 & 18.5 & 85 & 46 & 7.4 & 213.6 & 9.6 & 4.8 & 0 \\
\hline 28.4 & 23.2 & 88 & 85 & 7.5 & 200.2 & 1.9 & 3.6 & 1 \\
\hline 28 & 23 & 68 & 60 & 11.8 & 231 & 0 & 2.3 & 1 \\
\hline 33 & 22.7 & 84 & 74 & 6.4 & 182.4 & 5.3 & 2.6 & 1 \\
\hline 32.6 & 20 & 93 & 34 & 14.1 & 405 & 8.8 & 7.8 & 1 \\
\hline
\end{tabular}


pre-processing phase. The eight conditional variables and one decision variable in the target dataset are represented as: Maximum temperature (a1), Minimum temperature (a2), Relative humidity1 (a3), Relative humdity2 (a4), Wind speed (a5), Solar radiation (a6), Sunshine (a7), Evapotranspiration (a8) and Rainfall (Rf). The rainfall ( $\mathrm{Rf})$ is a binary decision variable; $(\mathrm{Rf}=0) \rightarrow$ no rainfall and $(\mathrm{Rf}=1) \rightarrow$ rainfall occurrence. The sample target dataset used as input for the proposed investigation is represented in Table 1.

\section{Rough Set Based Feature Selection Techniques}

Rough set based feature selection techniques are of wide ranges as shown in Figure 1. The reduct sets are generated based on rough sets discernibility matrix, indiscernibility matrix using the elements of the approximation space. The algorithms used for feature selection are of three types, namely filter, wrapper, and hybrid techniques. In this model, the discernible relation based wrapper technique has been adopted for feature selection.

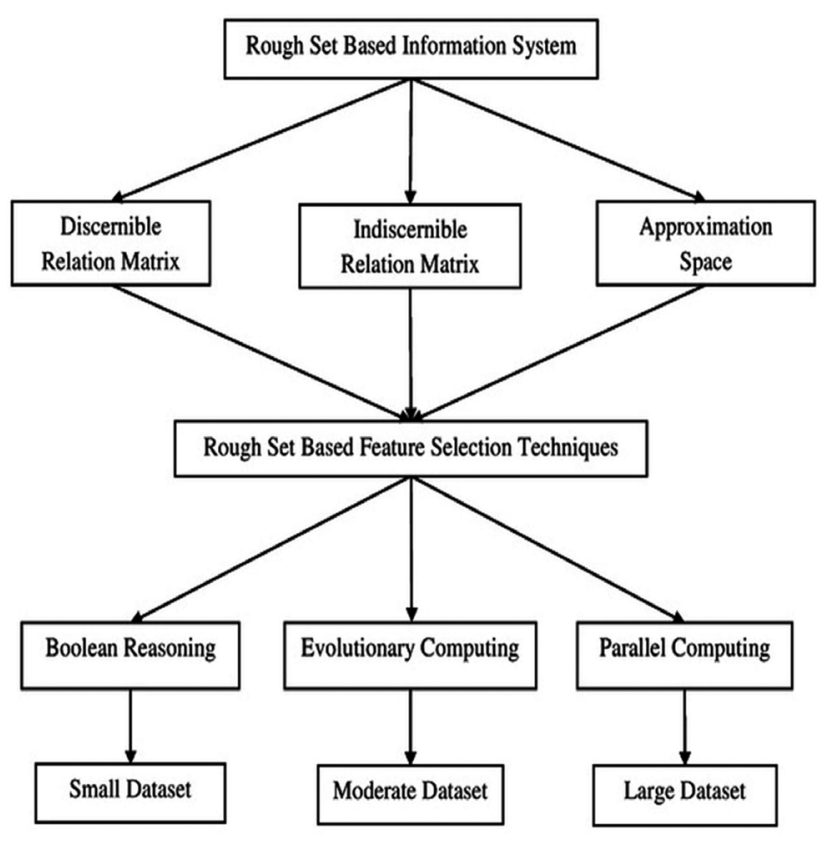

Figure 1. Rough set based feature reduction techniques.

\subsection{Input Data Selection Methodology}

This investigation identifies set of features as optimal feature reduct set from ' $n$ ' feature subsets generated using rough set genetic algorithm. The genetic algorithm is an evolutionary computational heuristic search that impersonates the human progression of evolution. This search strategy can generate solutions to achieve global optimization in search problems. A typical genetic algorithm procedure starts from the population of completely random individuals, and then it determines the fitness of the complete population. Each generation consists of some important operations, such as selection, crossover, mutation, and replacement. Few individuals in the existing population are replaced with new individuals to form a new population. Finally, this generational process is repeated, until a termination condition is reached. This input data selection phase introduces a novel rough set based MFW feature selection approach for computing the most relevant weather parameter for effective prediction. It is an exhaustive task having a suitable stopping criterion to terminate the selection process.

\subsection{Maximum Frequency Weighted Feature Reduction Technique}

MFW feature selection identifies the significant weather parameter from the complete set of re-

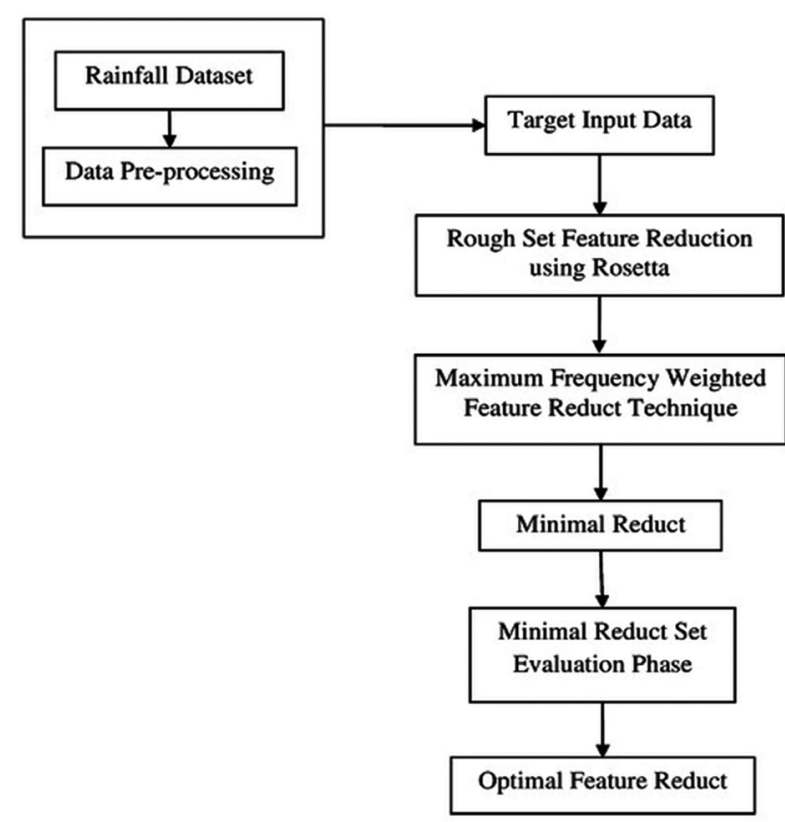

Figure 2. MFW feature reduction technique. 
duct sets based on the individual parameters frequency ranking. The target input dataset for the proposed MFW feature selection approach is partitioned as four segments, namely $\mathrm{d} 1, \mathrm{~d} 2$, $\mathrm{d} 3$, and $\mathrm{d} 4$ as shown in Table 2 for conducting a performance evaluation of the proposed approach. Table 3 projects the feature reduct subsets generated for each data partitions.

Table 2. Target input.

\begin{tabular}{|c|c|c|c|}
\hline \multirow{2}{*}{ Dataset } & \multicolumn{2}{|c|}{ Observatory Record } & Number of \\
\cline { 2 - 3 } & Years & Days & Instances \\
\hline \hline $\mathrm{d} 1$ & 6 & 310 & 2500 \\
\hline $\mathrm{d} 2$ & 13 & 255 & 5000 \\
\hline $\mathrm{d} 3$ & 20 & 200 & 7500 \\
\hline $\mathrm{d} 4$ & 27 & 145 & 10000 \\
\hline
\end{tabular}

The complete feature reduct sets $\mathrm{C}_{\mathrm{FRs}}\{\}$ for dataset $\mathrm{d} 1, \mathrm{~d} 2, \mathrm{~d} 3$ and $\mathrm{d} 4$ are determined using Rosetta. The minimal feature reduct set $\mathrm{M}_{\mathrm{FS}}\{\}$ for $\{\mathrm{d} 1, \mathrm{~d} 2, \mathrm{~d} 3$ and $\mathrm{d} 4\}$ and the optimal feature set $\mathrm{O}_{\mathrm{FRs}}\{\}$ for $\{\mathrm{d} 1, \mathrm{~d} 2, \mathrm{~d} 3$ and $\mathrm{d} 4\}$ are com- puted by MFW feature selection approach, as in Algorithm 1.

$\operatorname{Average}($ FreW $)=\frac{\sum(\text { frequency of all features })}{\text { total number of features }}$

The estimated frequency of each and every individual weather parameter (a1, a2, a3, a4, a5, a6, a7 and a8) for the dataset $\mathrm{d} 1, \mathrm{~d} 2, \mathrm{~d} 3$ and $\mathrm{d} 4$ are evaluated based on the proposed approach. Table 4 projects the obtained individual and average frequency rating of the features for each data partition. The set of features having their frequencies equal to or greater than the determined average frequency weighting $(\mathrm{FreW})$ as in Table 5 will constitute the minimal feature sets.

The average frequency rating as shown in Table 5 is the minimal feature subset selection criterion for the complete set of features. The set of features having frequency rating greater than or equal to $50.73 \%, 57.14 \%, 60.22 \%$, and $62.49 \%$ are identified as members in the minimal feature set of $\mathrm{d} 1, \mathrm{~d} 2, \mathrm{~d} 3$, and $\mathrm{d} 4$.

Table 3. Input for MFW feature reduction model.

\begin{tabular}{|c|c|c|c|}
\hline $\begin{array}{c}\text { d1 } \\
\text { Feature Subset }\end{array}$ & $\begin{array}{c}\mathrm{d} 2 \\
\text { Feature Subset }\end{array}$ & $\begin{array}{c}\text { d3 } \\
\text { Feature Subset }\end{array}$ & $\begin{array}{c}\text { d4 } \\
\text { Feature Subset }\end{array}$ \\
\hline$\{\mathrm{a} 1, \mathrm{a} 3, \mathrm{a} 5, \mathrm{a} 6\}$ & $\{\mathrm{a} 1, \mathrm{a} 2, \mathrm{a} 3, \mathrm{a} 4, \mathrm{a} 7\}$ & $\{\mathrm{a} 1, \mathrm{a} 2, \mathrm{a} 3, \mathrm{a} 4, \mathrm{a} 6\}$ & $\{\mathrm{a} 1, \mathrm{a} 2, \mathrm{a} 3, \mathrm{a} 5, \mathrm{a} 6\}$ \\
\hline$\{a 1, a 3, a 6, a 7\}$ & $\{\mathrm{a} 1, \mathrm{a} 2, \mathrm{a} 3, \mathrm{a} 6, \mathrm{a} 7\}$ & $\{a 1, a 2, a 3, a 5, a 6\}$ & $\{\mathrm{a} 1, \mathrm{a} 2, \mathrm{a} 4, \mathrm{a} 5, \mathrm{a} 7\}$ \\
\hline$\{\mathrm{a} 1, \mathrm{a} 4, \mathrm{a} 5, \mathrm{a} 6\}$ & $\{\mathrm{a} 1, \mathrm{a} 2, \mathrm{a} 4, \mathrm{a} 5, \mathrm{a} 7\}$ & $\{\mathrm{a} 1, \mathrm{a} 2, \mathrm{a} 4, \mathrm{a} 5, \mathrm{a} 6\}$ & $\{\mathrm{a} 1, \mathrm{a} 2, \mathrm{a} 5, \mathrm{a} 6, \mathrm{a} 7\}$ \\
\hline$\{\mathrm{a} 1, \mathrm{a} 5, \mathrm{a} 6, \mathrm{a} 7\}$ & $\{\mathrm{a} 1, \mathrm{a} 2, \mathrm{a} 4, \mathrm{a} 6, \mathrm{a} 7\}$ & $\{\mathrm{a} 1, \mathrm{a} 2, \mathrm{a} 4, \mathrm{a} 5, \mathrm{a} 7\}$ & $\{\mathrm{a} 1, \mathrm{a} 3, \mathrm{a} 4, \mathrm{a} 5, \mathrm{a} 7\}$ \\
\hline$\{a 2, a 3, a 4, a 5\}$ & $\{\mathrm{a} 1, \mathrm{a} 3, \mathrm{a} 4, \mathrm{a} 5, \mathrm{a} 7\}$ & $\{\mathrm{a} 1, \mathrm{a} 3, \mathrm{a} 4, \mathrm{a} 5, \mathrm{a} 7\}$ & $\{\mathrm{a} 1, \mathrm{a} 3, \mathrm{a} 4, \mathrm{a} 6, \mathrm{a} 7\}$ \\
\hline$\{\mathrm{a} 2, \mathrm{a} 3, \mathrm{a} 4, \mathrm{a} 6\}$ & $\{\mathrm{a} 1, \mathrm{a} 3, \mathrm{a} 5, \mathrm{a} 6\}$ & $\{\mathrm{a} 1, \mathrm{a} 3, \mathrm{a} 4, \mathrm{a} 6, \mathrm{a} 7\}$ & $\{\mathrm{a} 1, \mathrm{a} 4, \mathrm{a} 5, \mathrm{a} 6, \mathrm{a} 7\}$ \\
\hline$\{\mathrm{a} 2, \mathrm{a} 4, \mathrm{a} 5, \mathrm{a} 6\}$ & $\{\mathrm{a} 1, \mathrm{a} 3, \mathrm{a} 5, \mathrm{a} 6\}$ & $\{\mathrm{a} 2, \mathrm{a} 3, \mathrm{a} 4, \mathrm{a} 5, \mathrm{a} 6\}$ & $\{\mathrm{a} 2, \mathrm{a} 3, \mathrm{a} 4, \mathrm{a} 5, \mathrm{a} 6\}$ \\
\hline$\{a 2, a 4, a 5, a 7\}$ & $\{\mathrm{a} 1, \mathrm{a} 2, \mathrm{a} 3, \mathrm{a} 4, \mathrm{a} 7\}$ & $\{a 2, a 3, a 4, a 5, a 7\}$ & $\{\mathrm{a} 2, \mathrm{a} 3, \mathrm{a} 4, \mathrm{a} 6, \mathrm{a} 7\}$ \\
\hline$\{\mathrm{a} 2, \mathrm{a} 4, \mathrm{a} 6, \mathrm{a} 7\}$ & $\{\mathrm{a} 1, \mathrm{a} 2, \mathrm{a} 3, \mathrm{a} 6, \mathrm{a} 7\}$ & $\{\mathrm{a} 2, \mathrm{a} 3, \mathrm{a} 4, \mathrm{a} 6, \mathrm{a} 7\}$ & $\{\mathrm{a} 2, \mathrm{a} 3, \mathrm{a} 5, \mathrm{a} 6, \mathrm{a} 7\}$ \\
\hline$\{\mathrm{a} 2, \mathrm{a} 5, \mathrm{a} 6, \mathrm{a} 7\}$ & $\{\mathrm{a} 1, \mathrm{a} 2, \mathrm{a} 4, \mathrm{a} 5, \mathrm{a} 7\}$ & $\{\mathrm{a} 2, \mathrm{a} 5, \mathrm{a} 6, \mathrm{a} 7\}$ & $\{\mathrm{a} 2, \mathrm{a} 4, \mathrm{a} 5, \mathrm{a} 6, \mathrm{a} 7\}$ \\
\hline$\{a 3, a 4, a 5, a 6\}$ & $\{\mathrm{a} 1, \mathrm{a} 2, \mathrm{a} 4, \mathrm{a} 6, \mathrm{a} 7\}$ & $\{a 4, a 5, a 6, a 7\}$ & $\{\mathrm{a} 3, \mathrm{a} 4, \mathrm{a} 5, \mathrm{a} 6, \mathrm{a} 7\}$ \\
\hline$\{\mathrm{a} 3, \mathrm{a} 4, \mathrm{a} 5, \mathrm{a} 7\}$ & $\{\mathrm{a} 1, \mathrm{a} 3, \mathrm{a} 4, \mathrm{a} 5, \mathrm{a} 7\}$ & - & $\{\mathrm{a} 1, \mathrm{a} 2, \mathrm{a} 4, \mathrm{a} 5, \mathrm{a} 6\}$ \\
\hline$\{\mathrm{a} 3, \mathrm{a} 4, \mathrm{a} 6, \mathrm{a} 7\}$ & $\{\mathrm{a} 1, \mathrm{a} 3, \mathrm{a} 5, \mathrm{a} 6\}$ & - & $\{\mathrm{a} 2, \mathrm{a} 3, \mathrm{a} 4, \mathrm{a} 5, \mathrm{a} 7\}$ \\
\hline$\{\mathrm{a} 1, \mathrm{a} 2, \mathrm{a} 3, \mathrm{a} 4, \mathrm{a} 7\}$ & $\{\mathrm{a} 1, \mathrm{a} 4, \mathrm{a} 5, \mathrm{a} 6\}$ & - & - \\
\hline$\{\mathrm{a} 4, \mathrm{a} 5, \mathrm{a} 6, \mathrm{a} 7\}$ & - & - & - \\
\hline$\{a 1, a 2, a 5, a 7\}$ & - & - & - \\
\hline$\{\mathrm{a} 1, \mathrm{a} 3, \mathrm{a} 4, \mathrm{a} 6\}$ & - & - & - \\
\hline
\end{tabular}


Algorithm 1. MFW feature reduction algorithm

start

Initialize a set $\mathrm{C}_{\mathrm{FRs}}\{\}$ with $\mathrm{n}$ feature reducts

Initialize $\mathrm{j}=8$ (the number of features (a1, a2, a3, a4, a5, a6, a7 and a8)

Initialize an empty set Minimal Feature Set $\left(\mathrm{M}_{\mathrm{FRs}}\right)\{\}$

compute

Maximum Frequency Weight $\left(\mathrm{M}_{\mathrm{freW}}\right)=$ maximum number of prevalence of al in $\mathrm{C}_{\mathrm{FRs}}$

if $\mathrm{M}_{\mathrm{freW}} \geq$ Average $\left(\mathrm{F}_{\mathrm{reW}}\right)$ then include it in $\mathrm{M}_{\mathrm{FRs}}\{\}$ else ignore

j--

repeat (steps 1-4 [for all input parameter]) until $\mathrm{j}=0$ (stopping criteria)

return $\mathrm{M}_{\mathrm{FRs}}\{\}$

Initialize an Optimal Feature Reduct set $\mathrm{O}_{\mathrm{FRs}}\{\}$ (empty set)

compute

Evaluate the Prediction Accuracy of subsets of $\left\{\mathrm{M}_{\mathrm{FRs}}\right\}$ using classifiers

if prediction accuracy of $\left\{\mathrm{M}_{\mathrm{FRS}}\right\}=$ Peak Prediction Rate then include in $\mathrm{O}_{\mathrm{FRs}}\{\}$ else ignore return $\mathrm{O}_{\mathrm{FRs}}$

end

Table 4. Maximum Frequency Weight $\left(\mathrm{M}_{\mathrm{freW}}\right)$ Computaion.

\begin{tabular}{|c|c|c|c|c|c|}
\hline \multirow{2}{*}{ Feature } & \multirow{2}{*}{$\begin{array}{l}\text { La- } \\
\text { bel }\end{array}$} & \multicolumn{4}{|c|}{ Estimation of $M_{\text {freW }}(\%)$} \\
\hline & & d1 & d2 & d3 & d4 \\
\hline $\begin{array}{c}\text { Max } \\
\text { temperature }\end{array}$ & a1 & 41.17 & 100 & 54.54 & 53.84 \\
\hline $\begin{array}{c}\text { Mini } \\
\text { temperature }\end{array}$ & $\mathrm{a} 2$ & 47.05 & 57.14 & 72.72 & 69.23 \\
\hline $\begin{array}{c}\text { Relative } \\
\text { humidity } 1\end{array}$ & a3 & 52.94 & 57.14 & 63.63 & 61.53 \\
\hline $\begin{array}{c}\text { Relative } \\
\text { humidity } 2\end{array}$ & a4 & 70.58 & 57.14 & 81.81 & 76.92 \\
\hline Wind & a5 & 64.71 & 57.14 & 72.72 & 84.62 \\
\hline $\begin{array}{c}\text { Solar } \\
\text { radiation }\end{array}$ & $\mathrm{a} 6$ & 70.58 & 57.14 & 72.72 & 76.92 \\
\hline Sunshine & a7 & 58.82 & 71.42 & 63.63 & 76.92 \\
\hline $\begin{array}{l}\text { Evapotran- } \\
\text { spiration }\end{array}$ & a8 & 0 & 0 & 0 & 0 \\
\hline Average $(F$ & & 50.73 & 57.14 & 60.22 & 62.49 \\
\hline
\end{tabular}

Table 5. Minimal feature subset selection criterion.

\begin{tabular}{|c|c|}
\hline Dataset & Average (FreW) $(\%)$ \\
\hline \hline $\mathrm{d} 1$ & 50.73 \\
\hline $\mathrm{d} 2$ & 57.14 \\
\hline $\mathrm{d} 3$ & 60.22 \\
\hline $\mathrm{d} 4$ & 62.49 \\
\hline
\end{tabular}

Table 6. Minimal feature set.

\begin{tabular}{|c|c|c|c|}
\hline \multicolumn{4}{|c|}{ Minimal Feature Reduct Set } \\
\hline d1 & d2 & $\mathrm{d} 3$ & d4 \\
\hline $\begin{array}{c}\{\mathrm{a} 3, \mathrm{a} 4, \mathrm{a} 5, \\
\mathrm{a} 6, \mathrm{a} 7\}\end{array}$ & $\begin{array}{c}\{\mathrm{a} 1, \mathrm{a} 2, \mathrm{a} 4, \\
\mathrm{a} 5, \mathrm{a} 7\}\end{array}$ & $\begin{array}{c}\{\mathrm{a} 2, \mathrm{a} 4, \mathrm{a} 5 \\
\mathrm{a} 6, \mathrm{a} 7\}\end{array}$ & $\begin{array}{c}\{\mathrm{a} 2, \mathrm{a} 4, \mathrm{a} 5, \\
\mathrm{a} 6, \mathrm{a} 7\}\end{array}$ \\
\hline $\begin{array}{l}\{\mathrm{a} 4, \mathrm{a} 5 \\
\mathrm{a} 6, \mathrm{a} 7\}\end{array}$ & $\begin{array}{c}\{\mathrm{a} 1, \mathrm{a} 2, \mathrm{a} 4, \\
\mathrm{a} 6, \mathrm{a} 7\}\end{array}$ & $\begin{array}{c}\{\mathrm{a} 2, \mathrm{a} 3, \mathrm{a} 4 \\
\mathrm{a} 6, \mathrm{a} 7\}\end{array}$ & $\begin{array}{c}\{\mathrm{a} 2, \mathrm{a} 3, \mathrm{a} 4, \\
\mathrm{a} 5, \mathrm{a} 6\}\end{array}$ \\
\hline- & $\begin{array}{c}\{a 1, a 2, a 3, \\
a 4, a 7\}\end{array}$ & $\begin{array}{c}\{\mathrm{a} 2, \mathrm{a} 3, \mathrm{a} 4 \\
\mathrm{a} 5, \mathrm{a} 6\}\end{array}$ & $\begin{array}{c}\{\mathrm{a} 2, \mathrm{a} 3, \mathrm{a} 5, \\
\mathrm{a} 6, \mathrm{a} 7\}\end{array}$ \\
\hline- & $\begin{array}{c}\{\mathrm{a} 1, \mathrm{a} 3, \mathrm{a} 4, \\
\mathrm{a} 5, \mathrm{a} 7\}\end{array}$ & - & - \\
\hline
\end{tabular}

The proposed feature selection technique initially identifies the minimal feature reducts among the finite feature subsets. Then the performance of the minimal feature set was evaluated based on the classifier prediction accuracy. The subset with the highest prediction accuracy among the minimal feature set was then determined as optimal reduct. Following classifiers, namely, Naïve Bayes (NB), Bayesian Logistics Regression (BLR), Multi-Layer Perceptron (MLP), J48, Classification and Regression Tree (CART), Random Forest (RF) and SVM, were used for the evaluation. The optimal feature reduct is a minimal feature reducts set that attains the peak prediction accuracy. 


\section{Experimental Results and Discussions}

Minimal feature sets were assessed in terms of accuracy rate, to identify the optimal features using WEKA Software. Weka is a reliable open source machine learning and data mining tool widely adopted for a wide range of applications [31]. The accuracy rate is the percentage of instances that are correctly classified by the classifier for the specified testing and training set using 10-fold cross-validation in WEKA. In 10 -fold cross-validation, the model accuracy is calculated as the average error across the ten folds. The key point of this cross-validation is that it uses every possible sample for testing, and it can avoid an ill-fated split. A confusion matrix is expected as the most relevant measure for 10 -fold cross-validation. The classifier performance for the reduct set was estimated using confusion matrix and accuracy was estimated from the confusion matrix as given in equation (3). The confusion matrix describes the actual and predicted classification done by each classifier individually. The prediction accuracy of classifiers before MFW feature selection is given in Tables 7 to 10 . The minimal feature subsets projected in Table 6 is determined based on the selection criteria as represented in equation (2). The minimal and optimal feature reducts of proposed method are represented in Tables 11 and 14.

Accuracy Rate $\left(\mathrm{Ac}^{\mathrm{R}}\right)=\frac{\mathrm{Tp}+\mathrm{Tn}}{(\mathrm{Tp}+\mathrm{Tn}+\mathrm{Fp}+\mathrm{Fn})}$

[(Tp, Tn $)-$ True positive and True negative; (Fp, Fn) - False positive and False negative]

The seventeen reduct subsets generated using Rosetta for the data partition $\mathrm{d} 1$ and the classification accuracy achieved by NB, BLR, MLP, J48, CART, RF, and SVM are presented in Table 7 .

The fourteen and eleven reduct subsets generated using Rosetta for the data partition $\mathrm{d} 2$ and $\mathrm{d} 3$ and the classification accuracy achieved by NB, BLR, MLP, J48, CART, RF, and SVM are presented in Tables 8 and 9.

The thirteen reduct subsets generated using Rosetta for the data partition $\mathrm{d} 4$ and the classification accuracy achieved by NB, BLR, MLP, J48, CART, RF, and SVM are presented in Table 10.

Table 7. Prediction accuracy of 2500 days observatory records (d1).

Prediction Accuracy of Classifiers before MFW Feature Reduction

\begin{tabular}{|c|c|c|c|c|c|c|c|}
\hline \multirow{2}{*}{$\begin{array}{c}\text { d1 } \\
\text { Reducts } \\
\end{array}$} & \multicolumn{7}{|c|}{ Prediction Accuracy (\%) } \\
\hline & NB & BLR & MLP & $\mathrm{J} 48$ & CART & RF & SVM \\
\hline$\{\mathrm{a} 1, \mathrm{a} 2, \mathrm{a} 3, \mathrm{a} 4, \mathrm{a} 7\}$ & 82.68 & 79.68 & 85.12 & 83.8 & 84.28 & 86.4 & 84.56 \\
\hline$\{\mathrm{a} 4, \mathrm{a} 5, \mathrm{a} 6, \mathrm{a} 7\}$ & 86.24 & 77.44 & 89.56 & 89.72 & 89.04 & 86.4 & 89.04 \\
\hline$\{\mathrm{a} 1, \mathrm{a} 2, \mathrm{a} 5, \mathrm{a} 7\}$ & 79.64 & 80.44 & 83.6 & 81.52 & 82.08 & 86.4 & 82.08 \\
\hline$\{\mathrm{a} 1, \mathrm{a} 3, \mathrm{a} 4, \mathrm{a} 6\}$ & 86.48 & 79.84 & 88.16 & 87.84 & 88.2 & 79.84 & 88.2 \\
\hline$\{\mathrm{a} 1, \mathrm{a} 3, \mathrm{a} 5, \mathrm{a} 6\}$ & 85.68 & 77.44 & 87.04 & 87.08 & 87.36 & 77.44 & 88.16 \\
\hline$\{a 1, a 3, a 6, a 7\}$ & 88.24 & 77.48 & 89.64 & 88.76 & 89.16 & 77.48 & 89.4 \\
\hline$\{\mathrm{a} 1, \mathrm{a} 4, \mathrm{a} 5, \mathrm{a} 6\}$ & 86.4 & 77.92 & 88.4 & 88.04 & 88.16 & 77.92 & 82.56 \\
\hline$\{a 1, a 5, a 6, a 7\}$ & 86.76 & 77.48 & 89.52 & 89.16 & 89.4 & 89.02 & 88.4 \\
\hline$\{\mathrm{a} 2, \mathrm{a} 3, \mathrm{a} 4, \mathrm{a} 5\}$ & 80.28 & 77.4 & 82.24 & 81.36 & 82.56 & 82.24 & 89.52 \\
\hline$\{\mathrm{a} 2, \mathrm{a} 3, \mathrm{a} 4, \mathrm{a} 6\}$ & 87.56 & 78.28 & 88.72 & 87.8 & 88.01 & 82.24 & 82.24 \\
\hline$\{\mathrm{a} 2, \mathrm{a} 4, \mathrm{a} 5, \mathrm{a} 6\}$ & 86.4 & 77.4 & 88.62 & 87.87 & 88.54 & 82.24 & 86.81 \\
\hline$\{\mathrm{a} 2, \mathrm{a} 4, \mathrm{a} 5, \mathrm{a} 7\}$ & 81.94 & 78.57 & 85.36 & 85.22 & 84.92 & 77.44 & 85.83 \\
\hline$\{a 2, a 4, a 6, a 7\}$ & 86.81 & 77.44 & 89.18 & 89.44 & 89.39 & 77.44 & 86.35 \\
\hline$\{\mathrm{a} 2, \mathrm{a} 5, \mathrm{a} 6, \mathrm{a} 7\}$ & 85.83 & 77.44 & 89.72 & 89.02 & 89.41 & 78.30 & 79.12 \\
\hline$\{\mathrm{a} 3, \mathrm{a} 4, \mathrm{a} 5, \mathrm{a} 6\}$ & 86.35 & 78.3 & 88.45 & 88.28 & 88.62 & 88.4 & 86.81 \\
\hline$\{\mathrm{a} 3, \mathrm{a} 4, \mathrm{a} 5, \mathrm{a} 7\}$ & 79.92 & 80.6 & 81.32 & 80.25 & 81.17 & 89.52 & 85.83 \\
\hline$\{\mathrm{a} 3, \mathrm{a} 4, \mathrm{a} 6, \mathrm{a} 7\}$ & 87.37 & 77.8 & 89.34 & 89.66 & 89.48 & 82.24 & 86.35 \\
\hline
\end{tabular}


Table 8. Prediction accuracy of 5000 days observatory records (d2).

\begin{tabular}{|c|c|c|c|c|c|c|c|}
\hline d2 & \multicolumn{7}{|c|}{ Prediction Accuracy (\%) } \\
\hline Reducts & NB & BLR & MLP & $\mathrm{J} 48$ & CART & $\mathbf{R F}$ & SVM \\
\hline$\{\mathrm{a} 1, \mathrm{a} 2, \mathrm{a} 3, \mathrm{a} 4, \mathrm{a} 7\}$ & 80.96 & 82.68 & 83.28 & 83.14 & 82.68 & 81.64 & 82.33 \\
\hline$\{\mathrm{a} 1, \mathrm{a} 2, \mathrm{a} 3, \mathrm{a} 6, \mathrm{a} 7\}$ & 82.52 & 80.74 & 84.92 & 83.9 & 84.52 & 81.24 & 81.38 \\
\hline$\{\mathrm{a} 1, \mathrm{a} 2, \mathrm{a} 4, \mathrm{a} 5, \mathrm{a} 7\}$ & 79.84 & 82.62 & 83.78 & 83.08 & 82.9 & 81.64 & 81.02 \\
\hline$\{\mathrm{a} 1, \mathrm{a} 2, \mathrm{a} 4, \mathrm{a} 6, \mathrm{a} 7\}$ & 81.64 & 81.38 & 83.5 & 83.32 & 83.78 & 81.24 & 81.38 \\
\hline$\{\mathrm{a} 1, \mathrm{a} 3, \mathrm{a} 4, \mathrm{a} 5, \mathrm{a} 7\}$ & 81.24 & 81.02 & 82.98 & 83.14 & 82.9 & 84.92 & 81.02 \\
\hline$\{\mathrm{a} 1, \mathrm{a} 3, \mathrm{a} 5, \mathrm{a} 6\}$ & 79.11 & 80.74 & 81.5 & 82.66 & 82.82 & 83.78 & 80.74 \\
\hline$\{\mathrm{a} 1, \mathrm{a} 5, \mathrm{a} 6, \mathrm{a} 7\}$ & 79.56 & 80.74 & 82.94 & 82.5 & 83.32 & 84.92 & 83.91 \\
\hline$\{\mathrm{a} 1, \mathrm{a} 2, \mathrm{a} 3, \mathrm{a} 4, \mathrm{a} 7\}$ & 80.96 & 82.68 & 83.28 & 83.14 & 82.68 & 83.78 & 81.38 \\
\hline$\{\mathrm{a} 1, \mathrm{a} 2, \mathrm{a} 3, \mathrm{a} 6, \mathrm{a} 7\}$ & 82.52 & 80.74 & 84.92 & 83.9 & 84.52 & 84.52 & 84.55 \\
\hline$\{\mathrm{a} 1, \mathrm{a} 2, \mathrm{a} 4 \mathrm{a} 5, \mathrm{a} 7\}$ & 79.84 & 82.62 & 83.78 & 83.08 & 82.9 & 82.9 & 83.89 \\
\hline$\{\mathrm{a} 1, \mathrm{a} 2, \mathrm{a} 4, \mathrm{a} 6, \mathrm{a} 7\}$ & 81.64 & 81.38 & 83.5 & 83.32 & 83.78 & 83.78 & 82.62 \\
\hline$\{\mathrm{a} 1, \mathrm{a} 3, \mathrm{a} 4, \mathrm{a} 5, \mathrm{a} 7\}$ & 81.24 & 81.02 & 82.98 & 83.14 & 82.9 & 82.9 & 82.45 \\
\hline$\{\mathrm{a} 1, \mathrm{a} 3, \mathrm{a} 5, \mathrm{a} 6\}$ & 79.01 & 80.74 & 81.5 & 82.66 & 82.82 & 82.82 & 82.13 \\
\hline$\{\mathrm{a} 1, \mathrm{a} 5, \mathrm{a} 6, \mathrm{a} 7\}$ & 79.56 & 80.74 & 82.94 & 82.5 & 83.32 & 82.32 & 82.08 \\
\hline
\end{tabular}

Table 9. Prediction accuracy of 7500 days observatory records (d3).

\begin{tabular}{|c|c|c|c|c|c|c|c|}
\hline $\mathbf{d 3}$ & \multicolumn{7}{|c|}{ Prediction Accuracy (\%) } \\
\hline Reducts & NB & BLR & MLP & J48 & CART & \multicolumn{1}{c|}{ RF } & SVM \\
\hline \hline$\{\mathrm{a} 1, \mathrm{a} 2, \mathrm{a} 3, \mathrm{a} 4, \mathrm{a}\}$ & 81.4 & 80.19 & 82.92 & 82.69 & 83.48 & 80.92 & 82.92 \\
\hline$\{\mathrm{a} 1, \mathrm{a} 2, \mathrm{a} 3, \mathrm{a} 5, \mathrm{a}\}\}$ & 80.57 & 80.11 & 82.56 & 81.79 & 82.51 & 82.48 & 81.48 \\
\hline$\{\mathrm{a} 1, \mathrm{a} 2, \mathrm{a} 4, \mathrm{a} 5, \mathrm{a}\}$ & 80.57 & 80.11 & 82.56 & 81.79 & 82.51 & 82.27 & 82.03 \\
\hline$\{\mathrm{a} 1, \mathrm{a} 2, \mathrm{a} 4, \mathrm{a} 5, \mathrm{a} 7\}$ & 79.6 & 80.43 & 82.4 & 81.97 & 82.71 & 81.66 & 81.97 \\
\hline$\{\mathrm{a} 1, \mathrm{a} 3, \mathrm{a} 4, \mathrm{a} 5, \mathrm{a} 7\}$ & 80.64 & 80.59 & 82.52 & 82.35 & 83.04 & 82.77 & 82.31 \\
\hline$\{\mathrm{a} 1, \mathrm{a} 3, \mathrm{a} 4, \mathrm{a}, \mathrm{a} 7\}$ & 80.29 & 78.88 & 81.77 & 82.48 & 82.07 & 82.56 & 81.79 \\
\hline$\{\mathrm{a} 2, \mathrm{a} 3, \mathrm{a} 4, \mathrm{a} 5, \mathrm{a} 6\}$ & 81.29 & 78.92 & 81.56 & 82.57 & 82.72 & 81.55 & 81.22 \\
\hline$\{\mathrm{a} 2, \mathrm{a} 3, \mathrm{a} 4, \mathrm{a} 5, \mathrm{a} 7\}$ & 80.55 & 79.95 & 81.96 & 82.61 & 82.68 & 82.35 & 82.35 \\
\hline$\{\mathrm{a} 2, \mathrm{a} 3, \mathrm{a} 4, \mathrm{a} 6, \mathrm{a} 7\}$ & 80.29 & 78.88 & 81.77 & 82.48 & 82.07 & 82.15 & 82.04 \\
\hline$\{\mathrm{a} 2, \mathrm{a} 5, \mathrm{a} 6, \mathrm{a} 7\}$ & 76 & 77.44 & 79.81 & 79.71 & 80.32 & 80.85 & 81.08 \\
\hline$\{\mathrm{a} 4, \mathrm{a} 5, \mathrm{a} 6, \mathrm{a} 7\}$ & 79.59 & 78.57 & 80.71 & 80.87 & 81.08 & 81.55 & 79.91 \\
\hline
\end{tabular}

The possible minimal reduct sets generated using MFW feature selection technique for the data partition $\mathrm{d} 1, \mathrm{~d} 2, \mathrm{~d} 3$, and $\mathrm{d} 4$ and the classification accuracy achieved by NB, BLR, MLP, J48, CART, RF, and SVM are presented in Table 11

\subsection{Comparative Analysis}

The names and parameters for Weka's exhaustive search based feature selection algorithm used for comparative study is given below.
Exhaustive Search Based Feature Selection (existing method)

Run information (Weka 3.7.12)

Evaluator: weka.attributeSelection.CfsSubsetEval

Search: weka.attributeSelection.ExhaustiveSearch

Relation: target input

Instances: $10000(\mathrm{~d} 4), 7500(\mathrm{~d} 3), 5000(\mathrm{~d} 3)$ and $2500(\mathrm{~d} 1)$

Attributes: 9 (a1, a2, a3, a4, a5, a6, a7, a8, and a9)

Evaluation mode: 10-fold cross-validation

Attribute selection 10-fold cross-validation seed: 1

Feature subset obtained using Exhaustive Search approach 
Table 10. Prediction accuracy of 10000 days observatory records (d4).

\begin{tabular}{|c|c|c|c|c|c|c|c|}
\hline $\mathbf{d 4}$ & \multicolumn{7}{|c|}{ Prediction Accuracy (\%) } \\
\hline Reducts & NB & BLR & MLP & J48 & CART & RF & SVM \\
\hline \hline$\{\mathrm{a} 1, \mathrm{a} 2, \mathrm{a} 3, \mathrm{a} 5, \mathrm{a} 6\}$ & 80.77 & 77.44 & 82.03 & 83.15 & 83.25 & 79.06 & 80.02 \\
\hline$\{\mathrm{a} 1, \mathrm{a} 2, \mathrm{a} 4, \mathrm{a} 5, \mathrm{a} 7\}$ & 80.23 & 80.69 & 82.7 & 82.63 & 82.73 & 77.45 & 81.04 \\
\hline$\{\mathrm{a} 1, \mathrm{a} 2, \mathrm{a} 5, \mathrm{a} 6, \mathrm{a} 7\}$ & 78.37 & 77.45 & 81.04 & 81.1 & 80.6 & 81.06 & 83.84 \\
\hline$\{\mathrm{a} 1, \mathrm{a} 3, \mathrm{a} 4, \mathrm{a} 5, \mathrm{a} 7\}$ & 81.34 & 81.06 & 83.84 & 83.33 & 83.63 & 80.39 & 83.42 \\
\hline$\{\mathrm{a} 1, \mathrm{a} 3, \mathrm{a} 4, \mathrm{a} 6, \mathrm{a} 7\}$ & 81.18 & 80.39 & 83.42 & 83.45 & 83.23 & 82.91 & 81.99 \\
\hline$\{\mathrm{a} 1, \mathrm{a} 4, \mathrm{a} 5, \mathrm{a}, \mathrm{a} 7\}$ & 80.29 & 81.11 & 81.67 & 82.06 & 82.2 & 82.11 & 82.34 \\
\hline$\{\mathrm{a} 2, \mathrm{a} 3, \mathrm{a} 4, \mathrm{a} 5, \mathrm{a} 6\}$ & 82.27 & 80.43 & 83.35 & 83.40 & 83.42 & 81.66 & 82.02 \\
\hline$\{\mathrm{a} 2, \mathrm{a} 3, \mathrm{a} 4, \mathrm{a} 6, \mathrm{a} 7\}$ & 81.08 & 80.56 & 83.11 & 82.8 & 83.17 & 83.26 & 82.44 \\
\hline$\{\mathrm{a} 2, \mathrm{a} 3, \mathrm{a} 5, \mathrm{a} 6, \mathrm{a} 7\}$ & 79.48 & 77.63 & 82.06 & 82.02 & 82.83 & 82.91 & 82.72 \\
\hline$\{\mathrm{a} 2, \mathrm{a} 4, \mathrm{a} 5, \mathrm{a} 6, \mathrm{a} 7\}$ & 79.97 & 80.59 & 82.26 & 82.33 & 81.99 & 81.02 & 80.39 \\
\hline$\{\mathrm{a} 3, \mathrm{a} 4, \mathrm{a} 5, \mathrm{a} 6, \mathrm{a} 7\}$ & 81.35 & 80.42 & 82.71 & 82.62 & 83.02 & 82.32 & 81.11 \\
\hline$\{\mathrm{a} 1, \mathrm{a} 2, \mathrm{a} 4, \mathrm{a} 5, \mathrm{a} 6\}$ & 81.39 & 80.59 & 82.65 & 82.56 & 82.45 & 82.11 & 80.43 \\
\hline$\{\mathrm{a} 2, \mathrm{a} 3, \mathrm{a} 4, \mathrm{a} 5, \mathrm{a} 7\}$ & 81.2 & 80.25 & 83.10 & 83.27 & 83.13 & 82.34 & 80.56 \\
\hline
\end{tabular}

Table 11. Minimal feature reduct sets Prediction Accuracy.

Prediction Accuracy of Classifiers After MFW Feature Reduction

\begin{tabular}{|c|c|c|c|c|c|c|c|c|}
\hline Dataset & Minimal Reducts & NB & BLR & MLP & J48 & CART & RF & SVM \\
\hline \hline \multirow{3}{*}{ d1 } & $\{a 3, a 4, a 5, a 6, a 7\}$ & 79.92 & 80.6 & 81.32 & 80.25 & 81.17 & 81.72 & 81.07 \\
\cline { 2 - 9 } & $\{a 4, a 5, a 6, a 7\}$ & 86.24 & 77.44 & 89.56 & 89.72 & 89.04 & 83.53 & 82.65 \\
\hline \multirow{4}{*}{ d2 } & $\{a 1, a 2, a 4, a 5, a 7\}$ & 79.84 & 82.62 & 83.78 & 83.08 & 82.90 & 82.11 & 81.02 \\
\cline { 2 - 9 } & $\{a 1, a 2, a 4, a 6, a 7\}$ & 81.64 & 81.38 & 83.5 & 83.32 & 83.78 & 83.45 & 81.38 \\
\cline { 2 - 9 } & $\{a 1, a 2, a 3, a 4, a 7\}$ & 80.96 & 82.68 & 83.28 & 83.14 & 82.68 & 83.07 & 82.33 \\
\cline { 2 - 9 } & $\{a 1, a 3, a 4, a 5, a 7\}$ & 81.24 & 81.02 & 82.98 & 83.14 & 82.90 & 81.57 & 82.45 \\
\hline \multirow{4}{*}{ d3 } & $\{a 2, a 4, a 5, a 6, a 7\}$ & 81.29 & 78.92 & 81.56 & 82.57 & 82.72 & 81.72 & 82.03 \\
\cline { 2 - 9 } & $\{a 2, a 3, a 4, a 6, a 7\}$ & 80.29 & 78.88 & 81.77 & 82.48 & 82.07 & 82.32 & 82.04 \\
\cline { 2 - 9 } & $\{a 2, a 3, a 4, a 5, a 6\}$ & 81.29 & 78.92 & 81.56 & 82.57 & 82.72 & 82.21 & 82.35 \\
\hline \multirow{3}{*}{ d4 } & $\{a 2, a 4, a 5, a 6, a 7\}$ & 79.17 & 80.59 & 82.26 & 82.33 & 81.99 & 82.32 & 80.39 \\
\cline { 2 - 9 } & $\{a 2, a 3, a 4, a 5, a 6\}$ & 82.27 & 80.43 & 83.35 & 83.4 & 83.42 & 83.01 & 82.02 \\
\cline { 2 - 8 } & $\{a 2, a 3, a 5, a 6, a 7\}$ & 79.48 & 77.63 & 82.06 & 82.02 & 82.83 & 81.79 & 82.72 \\
\hline
\end{tabular}

An existing exhaustive search based attribute selection approach was used for comparison and validation of the proposed MFW feature reduction model. The existing approach identified $\{a 3, a 4, a 7, a 8\},\{a 2, a 3, a 4, a 7, a 8\},\{a 2$, $\mathrm{a} 4, \mathrm{a} 6, \mathrm{a} 7, \mathrm{a} 8\}$, and $\{\mathrm{a} 2, \mathrm{a} 4, \mathrm{a} 6\}$ feature subsets for the input $\mathrm{d} 4, \mathrm{~d} 3, \mathrm{~d} 2$, and $\mathrm{d} 1$ as projected in Table 13 using WEKA (http://www.cs.waikato. ac.nz/ml/weka).

The optimal reduct set and the achieved prediction accuracy is shown in Table 14. The weather parameter values of optimal reduct sets for classifiers in achieving classification results are shown in Table 15.

The accuracy of subsets generated using the existing exhaustive search and the proposed MFW feature reduction approach have been thoroughly examined.

For the above investigational results presented in Table 7 to Table 14 the clasisfiers were set with default parameter values. Some of the parameters values for classifiers in achieving classification results are presented in Table 16. 
Table 12. Feature subsets generated using existing exhaustive search approach.

\begin{tabular}{|c|c|c|c|c|}
\hline \multirow{2}{*}{ Attributes } & \multicolumn{4}{|c|}{ Number of folds (\%) attribute } \\
\cline { 2 - 5 } & $\mathbf{d 4}$ & $\mathbf{d 3}$ & $\mathbf{d 2}$ & $\mathbf{d 1}$ \\
\hline \hline $\mathrm{a} 1$ (Max) & 0 & 0 & 0 & 0 \\
\hline $\mathrm{a} 2$ (Min) & 0 & 100 & 100 & 100 \\
\hline $\mathrm{a} 3$ (RH1) & 50 & 100 & 40 & 0 \\
\hline $\mathrm{a} 4$ (RH2) & 100 & 100 & 100 & 100 \\
\hline $\mathrm{a} 5$ (WS) & 0 & 0 & 0 & 0 \\
\hline $\mathrm{a} 6(\mathrm{SR})$ & 0 & 0 & 100 & 100 \\
\hline $\mathrm{a}$ ( (SS) & 100 & 100 & 100 & 20 \\
\hline a8 (EVP) & 100 & 100 & 100 & 0 \\
\hline Feature Subset & $\{\mathrm{a} 3, \mathrm{a} 4, \mathrm{a} 7, \mathrm{a} 8\}$ & $\{\mathrm{a} 2, \mathrm{a} 3, \mathrm{a} 4, \mathrm{a} 7, \mathrm{a} 8\}$ & $\{\mathrm{a} 2, \mathrm{a} 4, \mathrm{a} 6, \mathrm{a} 7, \mathrm{a} 8\}$ & $\{\mathrm{a} 2, \mathrm{a} 4, \mathrm{a} 6\}$ \\
\hline
\end{tabular}

Table 13. Prediction accuracy (\%) of reducts based on existing exhaustive search.

\begin{tabular}{|c|c|c|c|c|c|c|c|c|}
\hline Dataset & Reducts & NB & BLR & MLP & J48 & CART & RF & SVM \\
\hline \hline $\mathrm{d} 1$ & $\{\mathrm{a} 2, \mathrm{a} 4, \mathrm{a} 6\}$ & 86.22 & 81.56 & 87.09 & 88.12 & 86.53 & 84.34 & 88.07 \\
\hline $\mathrm{d} 2$ & $\{\mathrm{a} 2, \mathrm{a} 4, \mathrm{a} 6, \mathrm{a} 7, \mathrm{a} 8\}$ & 81.34 & 7921 & 82.5 & 79.04 & 81.08 & 79.67 & 81.07 \\
\hline $\mathrm{d} 3$ & $\{\mathrm{a} 2, \mathrm{a} 3, \mathrm{a} 4, \mathrm{a} 7, \mathrm{a} 8\}$ & 79.98 & 80.33 & 81.85 & 82.33 & 82.12 & 78.55 & 80.01 \\
\hline $\mathrm{d} 4$ & $\{\mathrm{a} 3, \mathrm{a} 4, \mathrm{a} 7, \mathrm{a} 8\}$ & 81.23 & 80.07 & 79.05 & 81.21 & 81.07 & 79.04 & 79.71 \\
\hline
\end{tabular}

Table 14. Prediction accuracy (\%) of optimal reducts based on MFW feature selection.

\begin{tabular}{|c|c|c|c|c|c|c|c|c|}
\hline Dataset & Optimal Reducts & NB & BLR & MLP & J48 & CART & RF & SVM \\
\hline \hline $\mathrm{d} 1$ & $\{\mathrm{a} 4, \mathrm{a} 5, \mathrm{a} 6, \mathrm{a} 7\}$ & 86.24 & 77.44 & 89.56 & 89.72 & 89.04 & 86.4 & 89.04 \\
\hline $\mathrm{d} 2$ & $\{\mathrm{a} 1, \mathrm{a} 2, \mathrm{a} 4, \mathrm{a} 6, \mathrm{a} 7\}$ & 81.64 & 81.38 & 83.5 & 83.32 & 83.78 & 81.24 & 81.38 \\
\hline $\mathrm{d} 3$ & $\{\mathrm{a} 2, \mathrm{a} 3, \mathrm{a} 4, \mathrm{a} 5, \mathrm{a} 6\}$ & 81.29 & 78.92 & 81.56 & 82.57 & 82.72 & 81.55 & 81.22 \\
\hline $\mathrm{d} 4$ & $\{\mathrm{a} 2, \mathrm{a} 3, \mathrm{a} 4, \mathrm{a} 5, \mathrm{a} 6\}$ & 82.27 & 80.43 & 83.35 & 83.4 & 83.42 & 81.66 & 82.02 \\
\hline
\end{tabular}

Table 15. Parameter values of optimal reduct for achieving better prediction accuracy.

\begin{tabular}{|c|c|c|c|c|c|c|}
\hline Dataset & Optimal Reduct & \multicolumn{5}{|c|}{ Parameter Value (Minimum - Maximum) Range } \\
\hline \hline $\mathrm{d} 1$ & $\{\mathrm{a} 4, \mathrm{a} 5, \mathrm{a} 6, \mathrm{a} 7\}$ & $12.0-27.7$ & $48.0-100.0$ & $10.0-96.0$ & $0.0-73.4$ & - \\
\hline $\mathrm{d} 2$ & $\{\mathrm{a} 1, \mathrm{a} 2, \mathrm{a} 4, \mathrm{a} 6, \mathrm{a} 7\}$ & $190-39.8$ & $2.5-27.7$ & $5.2-96.0$ & $45.6-576.0$ & $0.0-98.0$ \\
\hline $\mathrm{d} 3$ & $\{\mathrm{a} 2, \mathrm{a} 3, \mathrm{a} 4, \mathrm{a} 5, \mathrm{a} 6\}$ & $2.5-27.7$ & $14.7-100.0$ & $5.2-96.0$ & $0.0-227.5$ & $45.6-592.0$ \\
\hline $\mathrm{d} 4$ & $\{\mathrm{a} 2, \mathrm{a} 3, \mathrm{a} 4, \mathrm{a} 5, \mathrm{a} 6\}$ & $2.0-33.5$ & $5.0-100.0$ & $1.0-99.0$ & $0.0-227.5$ & $24.0-688.0$ \\
\hline
\end{tabular}

The rainfall prediction accuracy of proposed model when compared with some popular existing models as in Table 17 reveal that the proposed technique outperformed the existing approaches.

The classifiers trained using the feature subsets generated using MFW reduction technique have improved the prediction accuracy. CART and J48 classifier obtained $83.42 \%, 83.72 \%$, $83.78 \%$ and $89.72 \%$ prediction accuracy for dataset $\mathrm{d} 4, \mathrm{~d} 3, \mathrm{~d} 2$ and $\mathrm{d} 1$ respectively. MFW feature selection approach is capable of finding some set of suitable subsets rather than just finding one subset after the attribute evaluation.

From the possible combinations one can identify the indispensable attribute using the 'core' prop- 
Table 16. Classifier (default) parameter value.

\begin{tabular}{|c|l|}
\hline Classifiers & \multicolumn{1}{c|}{ Parameter values } \\
\hline \hline NB & Kernel estimator, default precision -0.1 \\
\hline BLR & $\begin{array}{l}\text { Distribution of the Prior }- \text { Gaussian, Hyper parameter Value }-0.27 \text {, Tolerance Value }-0.0005, \\
\text { threshold value }-0.5\end{array}$ \\
\hline MLP & Learning rate -0.3, momentum 0.2 , training time -500 , validation threshold -20 \\
\hline J48 & Confidence factor -0.25, minimum number of leaves in end nodes -2 \\
\hline CART & Minimum number of leaves in end nodes -2, num_fold_pruning -5 \\
\hline RF & Maximum depth -0, num_Tree -10 \\
\hline SVM & Kernel function - radial basis function, tolerance of termination criterion -0.001 \\
\hline
\end{tabular}

Table 17. Rainfall prediction accuracy (\%) of existing approaches.

\begin{tabular}{|c|c|c|c|}
\hline Literature & Meteorological Data Registered (Region) & Technique & Prediction Accuracy \\
\hline \hline$[32]$ & $\begin{array}{c}\text { Cuddalore in East Coast of India. Temperature, } \\
\text { dew point, wind speed, visibility }\end{array}$ & $\begin{array}{c}\text { Predictive a priori } \\
\text { Algorithm, K* } \\
\text { Algorithm }\end{array}$ & $75.72 \%$ \\
\hline$[33]$ & $\begin{array}{c}\text { Accuweather.com of Indian Meteorological } \\
\text { Department. (1998 to 2012) 9 Yrs. Humidity, } \\
\text { temperature, pressure, wind speed, and dew } \\
\text { point }\end{array}$ & $\begin{array}{c}\text { Supervised Learning } \\
\text { in Quest decision } \\
\text { tree using gain ratio } \\
\text { Decision Tree }\end{array}$ & $77.78 \%$ \\
\hline$[34]$ & $\begin{array}{c}\text { Assam (2007 - 2012) 6 Yrs. Minimum } \\
\text { temperature, maximum temperature, pressure, } \\
\text { wind direction, relative humidity }\end{array}$ & $\begin{array}{c}\text { Multiple Linear } \\
\text { Regression }\end{array}$ & $63 \%$ \\
\hline$[35]$ & $\begin{array}{c}\text { Dongtai - coastal city of East China. Pressure, } \\
\text { temperature, extreme maximum temperature, } \\
\text { relative humidity }\end{array}$ & $\begin{array}{c}\text { Tree Augmented Naïve } \\
\text { Bayes model Naïve } \\
\text { Bayes }\end{array}$ & $62.5 \% 50 \%$ \\
\hline
\end{tabular}

erty of rough set from equation (1) as defined by Pawlak. The experimental study of learning algorithms before and after using MFW feature selection revealed that the performance of the learning algorithms has been improved when trained using optimal feature set.

\section{Conclusion}

The novel MFW feature reduction has identified relative humidity2 (a4) and solar radiation (a6) as indispensable or core parameters for rainfall prediction according to RST. Experimental study and evaluations conducted using the optimal subset on classification algorithms indicated that the accuracy rate of the classification models has improved after the feature selection using MFW feature selection approach. Experimental results conclude that this investigation has successfully identified the significant features for effective rainfall prediction by the proposed method. From the thorough inspection of all the classifiers, the trained feature reduct sets that contain the core features $\{\mathrm{a} 4$ and a6 $\}$ have achieved improved prediction rate. The experiment results revealed that the optimal reducts substantially reduced the computational and spatial complexity in processing large meteorological datasets. The proposed MFW feature selection technique has been identified as the optimal feature reducts from several reduct sets. The prediction accuracy of optimal reduct sets for the complete rainfall dataset achieved $83.42 \%$ accuracy when trained using CART. The experimental study indicates that the performance of prediction models has achieved enhanced rainfall prediction accuracy using MFWR compared to existing methods. 


\section{References}

[1] J. H. Seo and Y. H. Kim, "A survey on rainfall forecast algorithms based on machine learning technique", in Proceedings of the KIIS Fall Conference, Korea, 2011.

[2] G. E. Afandi et al., "Heavy rainfall simulation over Sinai Peninsula using the weather research and forecasting model", International Journal of Atmospheric Sciences, p. 11, 2013.

[3] H. D. LEE et al., "Feature selection for heavy rain prediction using genetic algorithms", in International Symposium on Advanced Intelligent Systems, IEEE, Kobe, Japan, November 2012.

[4] Z. Pawlak et al., "Rough sets", Communications of the ACM, vol. 38, no. 11, pp. 89-95, 1995. http://dx.doi.org/10.1145/219717.219791

[5] Z. Pawlak and R. Slowinski, "Rough set approach to multi-attribute decision analysis", European Journal of Operational Research, vol. 72, no. 3, pp. 443-459, 1994.

http://dx.doi.org/10.1016/0377-2217(94)90415-4

[6] Z. Pawlak and R. Slowinski, "Decision analysis using rough sets", International Transactions on Operational Research, vol. 1, pp. 107-114, 1994. http://dx.doi.org/10.1016/0969-6016(94)90050-7

[7] Z. Pawlak, "Rough sets", International Journal of Information and Computer Sciences, vol. 11, no. 5, pp. 341-356, 1982.

http://dx.doi.org/10.1007/BF01001956

[8] Z. Pawlak, "Rough sets and its applications", Journal of Telecommunications and Information Technology, pp. 7-10, 2002.

[9] Z. Pawlak and A. Skowron, "Rough sets: some extensions", Information Sciences, vol. 177, pp. 28-40, 2007.

http://dx.doi.org/10.1016/j.ins.2006.06.007

[10] Q. Shen and R. Jensen, "Rough sets their extensions and applications", International Journal of Automation and Computing, vol. 4, no. 1, pp. 100-106, 2007.

http://dx.doi.org/10.1007/s11633-007-0217-y

[11] A. Ohrn, Rosetta technical reference manual, Department of Computer and Information Science, Norwegian University of Science and Technology, Trondheim, Norwa, 2001.

[12] J. N. K. Liu et al., "An improved Naive Bayesian classifier technique coupled with a novel input solution method", IEEE Transactions on Systems, Man and Cybernetics, vol. 31, no. 2, pp. 249-256, 2001.

http://dx.doi.org/10.1109/5326.941848
[13] E. A. Alikhashashneh and Q. A. Al-Radaideh, "Evaluation of discernibility matrix based reduct computation techniques", in International Conference on Computer Science and Software Engineering, 2013.

http://dx.doi.org/10.1109/csit.2013.6588762

[14] L. Ju, "Attribution reduction algorithm based on improved binary dicernibility matrix", in International Conference on Computer and Electrical Engineering, Chengdu, Sichuan, China, 2010.

[15] T. Kanik, "Hepatitis disease diagnosis using rough set modification of the pre-processing algorithm", in Proceedings in Information and Communication Technologies International Conference, Atlanta, Georgia, 2012.

[16] W. Hao and X. Zhang, A simplified discernibility matrix of the attribute selection method, International conference on Information Management, (2010).

[17] Y. Y. Yao and Y. Zhao, "Discernibility matrix simplification for constructing attribute reducts", Information Sciences, vol. 179, no. 5, pp. 867-882, 2009.

http://dx.doi.org/10.1016/j.ins.2008.11.020

[18] W. C. Hong, "Rainfall forecasting by technological machine learning models", Applied Mathematics and Computation, vol. 1, pp. 41-57, 2008. http://dx.doi.org/10.1016/j.amc.2007.10.046

[19] J. Dai and Q. Xu, "Attribute selection based on information gain ratio in fuzzy rough set theory with application to tumour classification", Applied Soft Computing, vol. 13, pp. 211-221, 2013. http://dx.doi.org/10.1016/j.asoc.2012.07.029

[20] Y. Huang and S. Chen, "An algorithm of attribute selection based on rough sets", Physics procedia, pp. 2025-2029, 2013.

[21] N. Suguna and G. Thanushkodi, "An independent rough set approach hybrid with artificial bee colony algorithm for dimensionality reduction", American Journal of Applied Sciences, vol. 8, no. 3, pp. 261-266, 2011.

http://dx.doi.org/10.3844/ajassp.2011.261.266

[22] T. Qablan and S. A. Shuqeir, "A reduct computation approach based on ant colony optimization", Basic Science and Engineering, vol. 21, no. 1, pp. 29-40, 2012.

[23] W. Wei et al., "A comparative study of rough sets for hybrid data", Information Sciences, vol. 190, pp. 1-16, 2012.

http://dx.doi.org/10.1016/j.ins.2011.12.006

[24] S. Greco et al., "Rough set theory for multi-criteria decision analysis", European Journal of Operational Research, pp. 1-47, 2001. http://dx.doi.org/10.1016/S0377-2217(00)00167-3 
[25] L. Yu, "Toward integrating feature selection algorithms for classification clustering", IEEE Transactions on Knowledge and Data Engineering, vol. 17, no. 4, pp. 291-502, 2005.

[26] B. N. Valmik and B. B. Meshra, "Modeling rainfall prediction using data mining method a bayesian approach", in 5th International Conference on Computational Intelligence, Modeling and Simulation, IEEE Computer Society Washington, DC, USA, 2013.

[27] D. Q. Miao et al., "Relative reducts in consistent and inconsistent decision tables of the Pawlak rough set model", Information Sciences, vol. 179, pp. 4140-4150, 2009.

http://dx.doi.org/10.1016/j.ins.2009.08.020

[28] S. Mahapatra et al., "Attribute selection in marketing: A rough set approach", IIMB Management Review, vol. 22, pp. 16-24, 2010.

http://dx.doi.org/10.1016/j.iimb.2010.03.001

[29] M. Sudha and B. Valarmathi, "Rainfall forecast analysis using rough set attribute reduction and data mining methods", Agris on-line Papers in Economics and Informatics, vol. 6, no. 4, pp. 145-154, 2014.

[30] M. Sudha and B. Valarmathi, "Exploration on rough set approach for feature selection based reduction", International Journal of Applied Engineering Research, vol. 8, no. 13, pp. 1555-1566, 2013.

[31] H. Witten and E. Frank. (2005). Data mining: practical machine learning tools and techniques (2nd ed.) [Online]. Available:

http://www.cs.waikato.ac.nz/ ml/weka/index.html

[32] T. R. Sivaramakrishnan and S. Meganathan, "Association rule mining and classifier approach for quantitative spot rainfall prediction", Journal of Theoretical and Applied Information Technology, vol. 34, no. 2, pp. 173-177, 2011.

[33] L. V. Narasimha Prasad and M. M. Naidu, "An efficient decision tree classifier to predict precipitation using gain ratio", The International Journal of Soft Computing and Software Engineering, vol. 3, pp. 674-682, 2013.

[34] P. S. Dutta and H. Tahbildar, "Prediction of rainfall using datamining technique over Assam", Indian Journal of Computer Science and Engineering, vol. 5, no. 2, pp. 85-91, 2014.

[35] X. Shengjun et al., "Precipitation's level prediction based on tree augmented naïve bayes model", Telkomnika Indonesian Journal of Electrical Engineering, vol. 12, no. 1, pp. 314-322, 2014. http://dx.doi.org/10.11591/telkomnika.v12i1.3997
Received: May, 2015

Revised: October, 2015

Accepted: October, 2015

Contact addresses:

Sudha Mohankumar

VIT University

Department of Information Technology

Near Katpadi Rd Vellore

Tamil Nadu - 632014

India

e-mail:msudha@vit.ac.in

Valarmathi Balasubramanian VIT University

Department of Software and Systems Engineering

Near Katpadi Rd Vellore

Tamil Nadu - 632014

India

e-mail: valarmathi.b@vit.ac.in

Sudha Mohankumar is Assistant Professor (SG), Information Technology Department, VIT University, Vellore. She has research interests in data mining, machine intelligence, and cryptography and information security. She is currently pursuing her doctoral work in data mining. She has 15 years of teaching and research experience. She has published several research papers in various national, international journals and conferences.

Valarmathi Balasubramanian is Associate Professor, Head of Software and Systems Engineering Department, VIT University, Vellore; received her doctoral degree in 2013 from the Anna University, India. She has about 22 years of teaching and research experience. She has research interests in data mining, NLP and information retrieval. She has published several research papers in various national, international journals and conferences. 